University of Nebraska - Lincoln

DigitalCommons@University of Nebraska - Lincoln

USDA National Wildlife Research Center - Staff

Publications

U.S. Department of Agriculture: Animal and Plant Health Inspection Service

2018

Behavioral and spatial responses of captive coyotes to human activity

Jeffrey T. Schultz

USDA National Wildlife Research Center, jeff.t.schultz@aphis.usda.gov

Julie K. Young

Utah State University, julie.k.young@aphis.usda.gov

Follow this and additional works at: https://digitalcommons.unl.edu/icwdm_usdanwrc

Part of the Life Sciences Commons

Schultz, Jeffrey T. and Young, Julie K., "Behavioral and spatial responses of captive coyotes to human activity" (2018). USDA National Wildlife Research Center - Staff Publications. 2140.

https://digitalcommons.unl.edu/icwdm_usdanwrc/2140

This Article is brought to you for free and open access by the U.S. Department of Agriculture: Animal and Plant Health Inspection Service at DigitalCommons@University of Nebraska - Lincoln. It has been accepted for inclusion in USDA National Wildlife Research Center - Staff Publications by an authorized administrator of DigitalCommons@University of Nebraska - Lincoln. 


\title{
Behavioral and spatial responses of captive coyotes to human activity
}

\author{
Jeffrey T. Schultz ${ }^{\mathrm{a}, *}$, Julie K. Young ${ }^{\mathrm{a}, \mathrm{b}}$ \\ a USDA-National Wildlife Research Center-Predator Research Facility, Millville, UT 84326, USA \\ ${ }^{\mathrm{b}}$ Department of Wildland Resources, Utah State University, Logan, UT 84322-5295, USA
}

A R T I C L E I N F O

\section{Keywords:}

Behavior

Captive care

Canis latrans

Enrichment

Space use

Human activity

\begin{abstract}
A B S T R A C T
Human interactions can alter an animal's behavior and utilization of its surroundings, and how this impacts the welfare of some captive wild animals is of growing concern. Structural enrichment shelters offer weather protection, reprieve space from other animals or humans, or resting space. Perimeter or open space may be important during periods of activity, such as foraging or play. This study addressed the effects of human activity on coyote behavioral budgeting and enclosure utilization. We predicted that human activity would affect coyote behavior and spatial utilization of enclosure space. Specifically, we hypothesized that human activity would prompt vigilant and other active behavior at enclosure perimeters, thereby reducing inactive behavior at shelter structures. Thirty male-female coyote pairs were observed while experimentally exposed to one hour of human activity and one hour with no human activity for 16 observation days over the course of a 28-day test period. Behavior was categorized (vigilant, not active, active) and enclosure features were identified as three discrete areas (perimeter, open area, enrichment structure). A log-linear model using scan data showed that behavior significantly varied by enclosure feature $(P<0.01)$, and human activity significantly affected captive coyote behavior $(\mathrm{P}<0.01)$ and enclosure feature utilization $(\mathrm{P}<0.01)$. Non-parametric Mann-Whitney $U$ tests using observed proportions at each condition of human activity showed that human activity increased vigilant behavior $(\mathrm{P}<0.01)$ while reducing inactive behavior $(\mathrm{P}<0.01)$. Additionally, during periods of human activity, coyotes decreased utilization of open areas $(P<0.01)$ and enrichment structures $(P<0.01)$ and increased perimeter use $(\mathrm{P}<0.01)$. This study illustrates that captive animals may switch activity levels in the presence of humans and may not choose more complex environments when active behaviors are stimulated. Thus, wild animals in captivity may benefit from having the choice to utilize multiple types of habitat, depending upon their natural biological tendencies.
\end{abstract}

\section{Introduction}

Animal spatial patterns result from the availability and utility of resources, but are also inextricably tied to behavioral motives. Correlating an animal's behavior to its use of the landscape helps illustrate the utility associated with selected environmental features. For instance, Gese et al. (1996) found that coyotes (Canis latrans) mainly rested and hunted in grasslands and meadows and traveled on roads or riparian areas. In the winter, coyotes actively select among available habitat for travel, disproportionately choosing to use groomed trails (Dowd et al., 2014). An animal's behavior may change because food resources, social organization, and physiology fluctuate across seasons (Bekoff and Wells, 1981). Behavior is also influenced by other species (Kitchen et al., 1999; Neale and Sacks, 2001). For example, fine-scale environmental conditions that incorporated factors such as predatory and anthropogenic threats best explained elk (Cervus elaphus) movement patterns (Frair et al., 2005). The complexity of animal spatial and behavioral relationships also depends on individual variability of movement strategies (Roshier et al., 2008). Incorporating behavioral aspects into a thorough investigation of animal space use is essential when an animal's perception and decision-making abilities can influence selection.

Identifying the use and functionality of selected environmental features can provide beneficial information for improving animal welfare of captive wildlife. A principal goal of many captive animal facilities is to have behavior of captive animals resemble behavior of wild counterparts. When captive wild animals retain wild behavior, it suggests satisfactory welfare (Gilloux et al., 1992). Where animals are captive for outreach and education, such as at zoos, animals exhibiting natural behavior will maximize visitor learning experience. Where facilities house animals for research, activity budgets of captive animals that mimic those of conspecifics in the wild can provide rationale to extend inference (Renner and Lussier, 2002; Shivik et al., 2009).

Animals in human care may occasionally demonstrate unnatural

\footnotetext{
* Corresponding author at: USDA-NWRC-Predator Research Facility, 4200 South 600 East Cache County Road, Millville, UT 84326 USA.

E-mail address: jeff.t.schultz@aphis.usda.gov (J.T. Schultz).
} 
behavior such as pacing, hair-pulling, or self-biting (Bayne, 2005). Although the occurrence of stereotypic behavior may insinuate insufficient welfare, it may be serving innate biological or physical functions (Mason, 1991). Demonstrations of non-wild behavior do not always indicate a decrease in welfare, since they may be modes for animals to attain control over their environment (Veasey et al., 1996). Even so, environmental enrichment can reduce incidences of some stereotypic behavior in captive animals and infer the improvement of their welfare (Shyne, 2006). The Association of Zoos and Aquariums (AZA, 2017) define enrichment as "a process to ensure that the behavioral and physical needs of an animal are being met by providing opportunities for species-appropriate behaviors and choices." Thus, environmental enrichment seeks to aid captive animals in matching the behavior of wild constituents by providing additional environmental choices that are biologically relevant. Enrichment can enhance an animal's ability to cope with acute stress and allow it to adapt to changing situations (Mellen and MacPhee, 2001). Evaluating spatial and behavioral animal responses to enrichment practices can improve the efficacy of enrichment programs.

Occurrences of human activity at captive animal facilities may disrupt behavior and activity levels of their inhabitants (Davey, 2007; Hosey, 2000). The presence of visitors at zoos can influence an animal's behavior and space use (Kuhar, 2008; Mallapur et al., 2005; Sekar et al., 2008; Wells, 2005), and have additional effects when visiting groups are larger (Larsen et al., 2014; Woolway and Goodenough, 2017). Similar to zoos, animals at research laboratories must cope with human interactions caused by caretakers, researchers, maintenance crews, or visiting groups. Daily husbandry and maintenance interruptions range from being fairly innocuous to slightly intrusive. Visitor occurrences can increase abnormal behavior that ultimately impacts the welfare of some captive animals (Mallapur et al., 2005). Facilities should monitor animal responses to human activity to appropriately manage the frequency and magnitude of human interaction events. Predictability and control are important aspects of an animal's welfare (Bassett and Buchanan-Smith, 2007), and environmental enrichment may allow opportunities for some captive animals to gain more control of their surroundings when disruptive human activity occurs (Carder and Semple, 2008; Fernandez et al., 2009).

Coyotes are ubiquitous across the contiguous USA and readily populate urban environments (Gehrt et al., 2009; Poessel et al., 2017). Responses to human interaction may vary among individual coyotes, but those living in urban areas typically co-occur with humans by partitioning their activity patterns, spatially or temporally, to maximize resources (Gehrt et al., 2009). Like urban coyotes, captive coyotes must cope with human disturbances on a daily basis. To gain a clearer understanding of how captive coyotes respond to human activity, this study aimed to evaluate behavioral and spatial responses during periods with and without human interruption. We hypothesize that human activity will affect coyote behavior as well as their spatial utilization of enclosure space by prompting vigilant and other active behavior that is often demonstrated at the enclosure perimeter, thereby reducing inactive behavior that may normally occur at shelter structures that offer protection and space to rest.

\section{Material and methods}

\subsection{Study overview}

The study was conducted at the United States Department of Agriculture (USDA)-Wildlife Services (WS)-National Wildlife Research Center's (NWRC) Predator Research Facility in Millville, UT, USA, which houses over 100 adult coyotes in captivity as mated pairs for research purposes. Captive coyotes are fed once a day by animal caretakers but other human contact is kept to a minimum to prevent any abnormal social bonding. Beyond routine daily care and maintenance, coyotes at the facility are also occasionally exposed to researchers during experiments and, even less commonly, to educational groups touring the facility in vehicles. Testing for this study occurred during winter months (January - March) of 2015 and 2016. Thirty male-female pairs of coyotes $(n=60)$ were randomly selected from all mated pairs in the captive colony. Males were vasectomized prior to the study, per facility standard operating procedures, to prevent successful breeding while housed with their mates during the experiment, which overlapped with breeding season. Each pair of coyotes was randomly assigned to an enclosure and subjected to the same treatment and control activity schedule for a 28 -day test period. Two test periods were completed each year, resulting in the evaluation of 16 coyote pairs that were tested in 2015 and 14 more coyote pairs that were examined in 2016. All study coyotes were adults, born and raised at the research facility, and housed together with their established mates in various types of outdoor enclosures. Research protocols were approved by the Institutional Animal Care and Use Committee at the National Wildlife Research Center (QA-2375) and Utah State University (Protocol \#2490) and meet International Guiding Principles for Biomedical Research Involving Animals.

Eight 0.6 ha enclosures were utilized, consisting of two human access gates and an animal capture kennel $(2 \mathrm{~m} \times 3 \mathrm{~m})$ with a concrete floor that was located at either the north or south corner (Fig. 1). Each enclosure was comprised of natural substrate, an automatic watering device situated adjacent to one of the gates, and two den boxes made of cylindrical PVC $(0.5 \mathrm{~m}$ high $\times 0.5 \mathrm{~m}$ diameter $)$ providing corn cob bedding (Green Products Company, Conrad, IA, USA) in each capture kennel. Three enrichment structures were provided in the main enclosure area, and in-ground den holes were collapsed or otherwise made inaccessible during the study. The enclosures remained vacant for 1-3 days before experimental coyote pairs were released into the

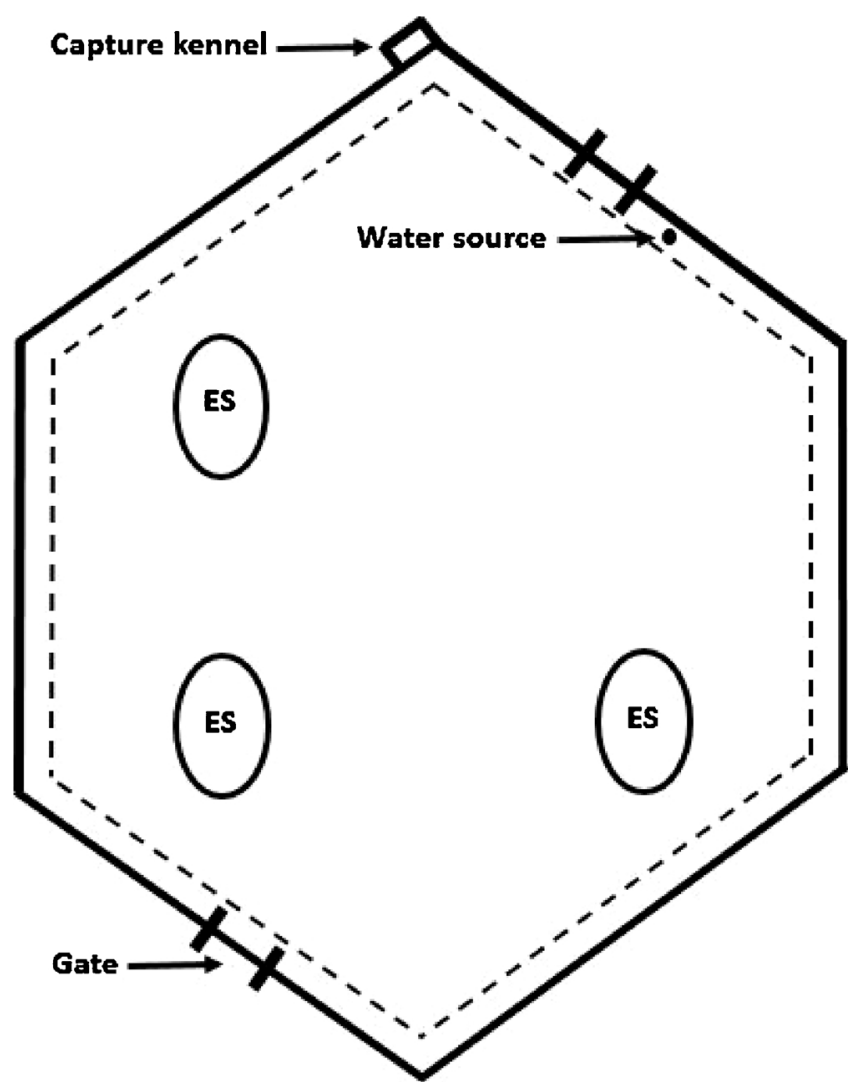

Fig. 1. Study enclosure for captive coyotes at the USDA-NWRC-Predator Research Facility. Enclosure features are depicted as ES (ovals denoting enrichment structure locations, perimeter (dashed lines delineating a 2-m perimeter zone that also incorporated a capture kennel located at one corner), and open area (other interior space). Depiction is not to scale. 
enclosures to allow for enrichment structure construction and feces removal. Scheduled observations began $\sim 24 \mathrm{~h}$ after the coyote pairs were transferred from their previously inhabited enclosures to their newly assigned experimental enclosures. Coyotes were scatter-fed normal daily rations ( $650 \mathrm{~g}$ per animal) of a commercially prepared food (Fur Breeders Agricultural Cooperative, Logan, UT, USA) in one specified area of each enclosure, and water was available ad libitum.

\subsection{Enrichment structures}

Experimental enrichment structures were assigned to one of three predetermined locations in the enclosures, spaced $40-55 \mathrm{~m}$ from each other and $>10 \mathrm{~m}$ from the perimeter fence (Fig. 1). They included two components: (1) a wooden shade table (to which coyotes have had previous exposure) and (2) an additional plywood platform $(1.2 \mathrm{~m} \times 1.2 \mathrm{~m})$ supported $1.2 \mathrm{~m}$ above the ground by four steel $\mathrm{T}$ posts. Combining the two components, each enrichment structure spanned $4 \mathrm{~m}$ in total length and were oriented in a north-south direction. Enrichment structures either comprised of the basic two components or had one extra feature (a ramp to access taller platform or three walls around the T-post supports).

\subsection{Behavioral observations}

Scan sampling was used for all behavioral observations (Altmann, 1974) using an innocuous mobile observation blind. Scans of each animal were conducted at 5-min intervals for two 1-h blocks per day, four days per week, over the duration of a 28-day period. One time block was randomly assigned to have human activity while human activity was abstained during the other time block. Human activity was standardized as follows: one caretaker drove an all-terrain vehicle (ATV) among the other non-study enclosures at the facility for the entire observation period. An ATV was used because it is the most commonly used mode of transportation by animal caretakers performing everyday animal care tasks at the facility. Although the coyotes appeared to ignore the observation blind, the observer arrived at the designated vantage point $15 \mathrm{~min}$ before beginning observations to assure coyotes resumed their normal activities if they responded to the blind. Start times were randomly selected between 08:00 and 15:00 to ensure sufficient light for visibility. At each scan, the location and behavior of the study coyote was logged. Coyotes were recorded at enrichment structures when they were within $2 \mathrm{~m}$ of a structure, and were considered at the perimeter when they were within $2 \mathrm{~m}$ of the perimeter fence. Behavior was categorized into three groups: vigilant, inactive, and active (Table 1). Only one person conducted all scans to eliminate inter-observer variability.

\subsection{Analysis}

The proportion of scans at each location and behavior were averaged across all individuals and reported with standard error (SE). Since the observed data did not follow normal distributions, non-parametric Mann-Whitney $U$ tests were performed to determine significant differences between the observed proportions at each condition of human activity. To statistically assess how the distribution of coyote behavior differed among locations and how human activity affected the distribution of behavior or utilization of enclosure features, a generalized linear mixed model (GLMM) was fitted with a negative binomial distribution. A coyote's response to human activity may involve both their behavior and the space they choose to use inside their enclosure. Since one of these factors may influence the other, we designed the GLMM as a log-linear mixed model using categorical data to produce marginal means for statistical comparison (Agresti, 2013). There was no apparent difference in behavior between the male and female coyotes within a pair, so sex was not included as a predictor variable in the model. The response variable was scan count, summed over all observations for both coyotes in a pair. Behavior type (active/inactive/ vigilant), enclosure feature (perimeter/open/enrichment structure), and human activity (no/yes) were fixed effects factors, and all interactions among these factors were included in the model. To accommodate correlation due to clustering of scans within pairs, pair was included as a random effects factor. Additionally, each behavior type was independently examined to assess change in occurrences over the course of the test period. Behaviors were first inspected with scatter plots, using scan count as the dependent variable and trial day as the independent variable. Three additional GLMMs (one model for each behavior) were also fit with negative binomial distributions where scan count was the response variable, trial day (1-28) and human activity (yes/no) were fixed effects factors, and pair was a random effects factor. All models were fitted using the glmmadmb function in the glmmADMB package (Skaug et al., 2013) in Program R, version 3.3.2 (R Core Team, 2016). Marginal means were derived from the log-linear model using the lsmeans function in the lsmeans package (Lenth, 2016), and comparisons among marginal means were computed using the contrast function in the lsmeans package. Family-wise Type I error was controlled using the Tukey method. The significance threshold was set at 0.05 .

\section{Results}

Human activity significantly increased perimeter utilization $(\mathrm{U}=379.5, \mathrm{P}<0.01)$ while coyotes significantly decreased utilization of open areas $(\mathrm{U}=2630, \mathrm{P}<0.01)$ and enrichment structures $(\mathrm{U}=2763.5, \mathrm{P}<0.01)$ (Fig. 2a). Human activity significantly increased vigilant behavior $(\mathrm{U}=30, \mathrm{P}<0.01)$ and significantly decreased inactive behavior ( $\mathrm{U}=3599, \mathrm{P}<0.01$ ) (Fig. $2 \mathrm{~b})$.

The log-linear GLMM showed human activity significantly affecting coyote behavior and utilization of different enclosure features (Table 2), and estimated marginal means are reported in Table 3. When there was no human activity, coyotes utilized open areas significantly more than enrichment structures $(P<0.01)$ and the perimeter $(\mathrm{P}=.02)$, with enrichment structures being used significantly less than the perimeter $(\mathrm{P}=.02)$. Vigilant and inactive behavior occurred significantly more than active behavior $(\mathrm{P}<0.01)$ when there was no human activity. When human activity occurred, coyotes utilized perimeter and open areas significantly more than enrichment structures $(\mathrm{P}<0.01)$. Human activity resulted in significantly more vigilant behavior than active or inactive behavior $(\mathrm{P}<0.01)$, and coyotes were significantly more active than inactive with human activity $(\mathrm{P}<0.01)$.

The log-linear GLMM also indicated significant variation in behavior at the different enclosure features (Table 2). Estimated marginal means are reported in Table 3. At enrichment structures, coyotes were

Table 1

Description of behavior categories from scan observations of captive coyotes during two 1-h blocks where one was with and one was without human activity.

\begin{tabular}{|c|c|}
\hline Behavior Category & Description \\
\hline Vigilant & Lying, sitting, standing, walking, or running with head raised and visually surveying the environment. \\
\hline Inactive & Lying and resting with head down or eyes closed (not vigilant); lying and grooming, sniffing or biting grass; sitting; standing and drinking or grooming. \\
\hline Active & $\begin{array}{l}\text { Running, walking, pacing, digging, sniffing with nose close to the ground while walking or standing; breeding activities such as mounting or sniffing, } \\
\text { dominant or subordinate playing or fighting, howling; marking (i.e., urinating or defecating then scratching, lying or rolling), stalking conspecifics, fence } \\
\text { running with vigilance directed at conspecifics. }\end{array}$ \\
\hline
\end{tabular}




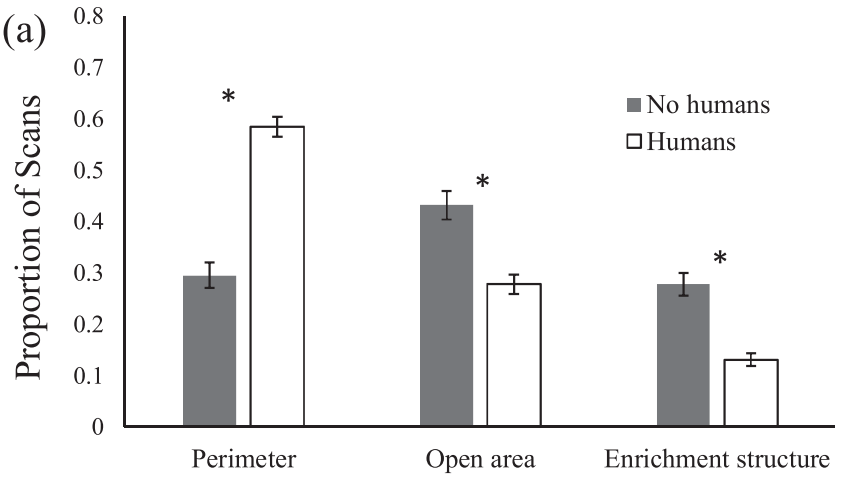

Enclosure Feature

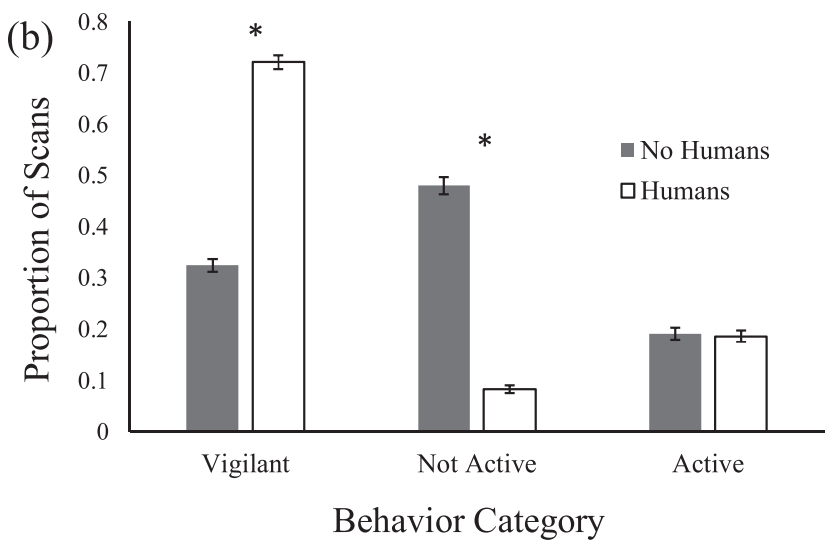

Fig. 2. Mean proportions of observed animal (a) enclosure features and (b) behavior with and without human activity. Error bars represent standard error (SE) of individual mean proportions and (*) signifies significant differences between periods with and without human activity. Means and SEs shown are computed by descriptive statistics that used raw data.

Table 2

Tests of main effects and interactions of generalized linear mixed model derived from scan data to predict frequencies of enclosure feature and behavior distributions of captive coyotes in relation to the absence or presence of human activity.

\begin{tabular}{llrr}
\hline Effect & df & \multicolumn{1}{c}{$\mathrm{X}^{2}$} & \multicolumn{1}{l}{$P$} \\
\hline Human activity & 1 & 41.1 & $<\mathbf{0 . 0 1}$ \\
Enclosure feature & 2 & 115.7 & $<\mathbf{0 . 0 1}$ \\
Behavior & 2 & 168.6 & $<\mathbf{0 . 0 1}$ \\
Human activity * behavior & 2 & 182.6 & $<\mathbf{0 . 0 1}$ \\
Human activity * enclosure feature & 2 & 10.6 & $<\mathbf{0 . 0 1}$ \\
Behavior * enclosure feature & 4 & 226.2 & $<\mathbf{0 . 0 1}$ \\
Human activity * behavior * enclosure feature & 4 & 3.1 & 0.53 \\
\hline
\end{tabular}

Bold denotes significance at the 0.05 level.

significantly more inactive and vigilant than active $(\mathrm{P}<0.01)$. Open areas realized significantly more vigilance than active $(\mathrm{P}<0.01)$ and inactive behavior $(\mathrm{P}=.01)$. Coyotes at the perimeter were also significantly more vigilant than active $(\mathrm{P}<0.01)$ or inactive $(\mathrm{P}<0.01)$, but were significantly more active than inactive $(\mathrm{P}<0.01)$.

There was no significant difference in vigilant or inactive behavior across trial days, but the GLMM analyzing active behavior indicated a significant difference in scan frequencies across trial days $(\mathrm{P}=.03)$. Visual inspection of the data suggest a slight decrease in recorded active counts along with their variance after day 12 of the test period.
Table 3

Model-estimated marginal means with standard error (SE) of significant twofactor interactions from generalized linear mixed model that used scan data to predict frequencies of enclosure feature and behavior distributions of captive coyotes in relation to the absence or presence of human activity. Marginal means with SE are reported on the log scale.

\begin{tabular}{llll}
\hline \multicolumn{2}{l}{ Human activity* behavior interaction: } \\
\hline Human Activity & Behavior & Marginal Mean & SE \\
\hline \multirow{2}{*}{ no } & vigilant & 3.70 & 0.11 \\
& not active & 4.01 & 0.08 \\
& active & 2.95 & 0.09 \\
yes & vigilant & 4.32 & 0.11 \\
& not active & 2.28 & 0.09 \\
& active & 2.75 & 0.09 \\
\hline
\end{tabular}

Human activity * enclosure feature interaction:

\begin{tabular}{llll}
\hline Human Activity & Enclosure Feature & Marginal Mean & SE \\
\hline \multirow{2}{*}{ no } & perimeter & 3.55 & 0.11 \\
& open area & 3.96 & 0.08 \\
& enrichment structure & 3.15 & 0.08 \\
yes & perimeter & 3.54 & 0.11 \\
& open area & 3.38 & 0.08 \\
& enrichment structure & 2.43 & 0.09 \\
\hline
\end{tabular}

Behavior * enclosure feature interaction:

\begin{tabular}{llll}
\hline Behavior & Enclosure Feature & Marginal Mean & SE \\
\hline \multirow{2}{*}{ vigilant } & perimeter & 4.48 & 0.17 \\
& open area & 4.09 & 0.13 \\
& enrichment structure & 3.45 & 0.13 \\
not active & perimeter & 2.51 & 0.14 \\
& open area & 3.58 & 0.10 \\
active & enrichment structure & 3.36 & 0.10 \\
& perimeter & 3.65 & 0.13 \\
& open area & 3.35 & 0.10 \\
& enrichment structure & 1.56 & 0.11 \\
\hline
\end{tabular}

\section{Discussion}

This study explored how behavior and utilization of different enclosure features changed with the presence or absence of human activity. It also examined the relationship between coyote behavior and their selection of certain environmental features. Results show that captive coyotes dynamically respond to the presence of human activity, altering behavior and utilization of different features relative to times without human activity. Human activity notably generated higher occurrences of vigilant behavior and caused coyotes to utilize perimeters and open areas more than enrichment structures. Coyotes often appeared to be vigilant, regardless of their surrounding environmental conditions, and mainly inactive at enrichment structures and open areas. Behavior at the perimeter, aside from being mostly vigilant, was more active than inactive.

Understanding the relationships of how human activity affected coyote behavior at different enclosure features was interesting to explore. Coyotes may have been more active at the perimeter when humans were present to gain a better vantage point for observing the human, which is supported by the accompanying increase in vigilant state. Wild coyotes have been observed tracking human activity and using vantage points for direct observations of humans (Séquin et al., 2003). Alternatively, an increase in perimeter use could be related to a natural tendency for coyotes to perform scent-marking behavior along the periphery of their territories (Gese and Ruff, 1997). Captive coyotes will often scent mark their enclosures and interact with neighbors while at the periphery (Schell et al., 2016). This behavior may increase during bouts of human activity as part of territorial maintenance against perceived outside threats (Allen et al., 1999). Although the third order interaction was not statistically significant in the GLMM, the model did 
support that behavioral and spatial distributions were each independently affected by human activity, and behavior was related to enclosure features.

Coyotes in this study spent slightly less than half of their time being inactive when there was no human activity. This is less time than observations of wild coyotes that reportedly spend upwards of $59 \%$ of their time resting (Gese et al., 1996). One possible explanation could be the differences in diurnal activity budgets between captive and wild coyotes. Another possible explanation could simply be due to slight differences in defining inactive behavior between studies. For example, captive coyotes that were lying but also displaying vigilance were recorded as being vigilant as opposed to inactive. Nonetheless, inactivity is a predominant natural behavior for coyotes, and captive facilities aiming to match wild behavior should monitor this phenomenon while not confusing it with the concept of animal boredom (Wemelsfelder, 1984).

When human activity occurred, coyotes shifted behavior from being highly inactive to predominantly vigilant, mostly with coyotes located at perimeters instead of open areas of the enclosures. This vigilant behavioral response differs from primates that may display increased aggressive behavior or felids that typically remain unaffected by visitor presence (Hosey, 2013, 2008). Accounts of vigilance toward humans by other wild animals in captivity have been interpreted to portray that the animals may perceive humans as enemies, but have partially habituated to the circumstance (Hosey, 2013). Coyotes may have increased vigilance in this study to assess threats that could be posed by humans. Wild coyotes increase vigilant behavior when gray wolves (Canis lupus) are present (Atwood and Gese, 2008; Switalski 2003), but the relationship between humans and coyotes in human care has not been investigated. Further examination into which direction (i.e., further from, closer to) coyotes moved in relation to the sources of human activity could better describe how they perceived human activity.

Some stereotypic behaviors (i.e., pacing, aggressive digging, grass pulling) were occasionally observed, insinuating a decrease in wellbeing (Mason, 1991; Shepherdson et al., 1993). Coyotes have been found to decrease the frequency of these non-wild behaviors with increased enclosure space (Brummer et al., 2010), and is why the experiment was conducted in large enclosures at the research facility. Stereotypic behavior was more often observed with the presence of human activity and may be related to predictable signals (Bassett and Buchanan-Smith, 2007). Stereotypic behaviors in captive animals can result from excitement, anxiety, or frustration (Mason, 1991). Coyotes at the research facility are fed once daily from caretakers using ATVs. Even though ATVs are used outside of feeding, coyotes may still highly anticipate a feeding event and it is likely that stereotypic behavior in this study was food-related. Captive coyote behavior has been noticed to differ with the predictability of food (Gilbert-Norton et al., 2009), which may cause shifts in the utilization of different enclosure features. We were unable to separate vigilant or active behaviors into categories related to observation versus anticipation and are therefore limited in our interpretation of these results. Vigilant and inactive behavior did not change over time, but a slight decrease in active behavior was noticed in the middle of the test period. This may suggest that some coyotes eventually could have habituated to the experimental human activity, disassociating it from feeding events which directly included them. If that was the case, then the vigilance observed in this study would represent a more natural behavioral state as opposed to an anticipatory behavior that results from a captive environment. Future studies could compare captive coyote responses to different types of human activity, such as feeding behavior versus an unfamiliar activity, to address this directly.

Coyotes were located at enrichment structures more often and were mainly inactive when there was no human activity. Enrichment structures and open areas had similar counts of inactive behavior when no human activity was occurring. Since the enrichment structures occupied a comparably small proportion of enclosure space, it appears that coyotes actively selected for complex environmental features when resting during undisturbed conditions. Other species of captive animals have been shown to exhibit preferences for more complex environments. Indian leopards (Panthera pardus) housed in more complex enclosures spent more time in the enriched areas compared to leopards housed in less complex enclosures (Mallapur et al., 2002). Captive red foxes (Vulpes vulpes) were also observed to utilize structurally enriched areas more than barren areas (Kistler et al., 2010). This study found that enrichment structures were used less during human activity events. Even though no in-ground dens were accessible, coyotes did not appear to hide at the structures when human disruption occurred. Instead, the enrichment structures were utilized for resting during periods of no human activity.

Recording and analyzing responses to environmental enrichment is critical for evaluating and refining enrichment programs (Mellen and MacPhee, 2001). This study helps advance environmental enrichment practices for captive coyotes and possibly other canids. Enrichment structures appear to be utilized for resting and vigilance. While these results provide insight into winter responses of captive coyotes to human activity, their behavior and enclosure utilization should also be evaluated in other seasons. Further, additional information could be assessed regarding pair dynamics. In this study we evaluated individual behavioral and spatial responses and controlled for pair within analysis, but it is likely that individuals within each pair influence one another. However, this influence may be minimal as canids are known to travel alone, especially to increase foraging efficiency when hunting small mammals (de Almeida Jácomo et al., 2009; Kitchen et al., 2005; Poulle et al., 1994; White et al., 2000). Evaluating whether pairs of captive coyotes spatially or behaviorally respond to one another could inform captive care and our understanding of coyote social dynamics. Finally, we relied on one observer throughout the study. While this method eliminates inter-observer bias, it may have introduced intra-observer error, especially in the form of observational drift (Kazdin, 1977). Given the location used in this study to observe all test enclosure areas, it was not possible to video record coyote behavior to test for intraobserver error across time. Doing so could improve similar studies in the future.

\subsection{Conclusions}

Coyotes clearly alter their behavioral and spatial tendencies in response to human activity, indicating an inherent capacity to quickly adapt to changing environments. This poses questions regarding their perception of humans and any risks or rewards they may associate with instances of human interaction. Researchers could consider this when designing future studies. Correlating animal behavior to the utilization of environmental features adds an informative and realistic dimension to captive animal care and welfare. Captive facilities should provide features that accommodate the natural tendencies of their animals, and monitor behavioral responses to human activity events. This study illustrates that captive animals may switch activity levels in the presence of humans and may not utilize complex environments when active behaviors are stimulated. Thus, most wild animals in captivity may benefit from having the choice to utilize multiple types of habitat.

\section{Conflicts of interest}

None.

\section{Acknowledgements}

We thank S. Brummer, M. Davis, N. Floyd, B. Jolley, E. Stevenson, E. Wright, and several volunteers with assistance conducting the field work. S. Friedman, E. Gese, and two reviewers provided excellent reviews of the manuscript. We also thank S. Durham for statistical advice. Funding was provided by USDA-National Wildlife Research Center. 


\section{References}

Association of Zoos and Aquariums, 2017. AZA Accreditation Standards. https://www aza.org/assets/2332/aza-accreditation-standards.pdf. (Accessed 20 April 17).

Agresti, A., 2013. Categorical Data Analysis, third ed. Hoboken, New Jersey.

Allen, J.J., Bekoff, M., Crabtree, R.L., 1999. An observational study of coyote (Canis latrans) scent-marking and territoriality in Yellowstone National Park. Ethology 105 (4), 289-302.

Altmann, J., 1974. Observational study of behavior: sampling methods. Behaviour 49, 227-267.

Atwood, T.C., Gese, E.M., 2008. Coyotes and recolonizing wolves: social rank mediates risk-conditional behaviour at ungulate carcasses. Anim. Behav. 75 (3), 753-762.

Bassett, L., Buchanan-Smith, H.M., 2007. Effects of predictability on the welfare of captive animals. Appl. Anim. Behav. Sci. 102, 223-245. http://dx.doi.org/10.1016/j. applanim.2006.05.029.

Bayne, K., 2005. Potential for unintended consequences of environmental enrichment for laboratory animals and research results. ILAR J. 46, 129-139.

Bekoff, M., Wells, M.C., 1981. Behavioral budgeting by wild coyotes: the influence of food resources and social organization. Anim. Behav. 29, 794-801.

Brummer, S.P., Gese, E.M., Shivik, J.A., 2010. The effect of enclosure type on the behavior and heart rate of captive coyotes. Appl. Anim. Behav. Sci. 125, 171-180. http://dx. doi.org/10.1016/j.applanim.2010.04.012.

Carder, G., Semple, S., 2008. Visitor effects on anxiety in two captive groups of western lowland gorillas. Appl. Anim. Behav. Sci. 115, 211-220. http://dx.doi.org/10.1016/j. applanim.2008.06.001.

Davey, G., 2007. Visitors' effects on the welfare of animals in the zoo: a review. J. Appl. Anim. Welf. Sci. 10, 169-183. http://dx.doi.org/10.1080/10888700701313595.

de Almeida Jácomo, A.T., Kashivakura, C.K., Ferro, C., Furtado, M.M., Astete, S.P., Tôrres, N.M., Sollmann, R., Silveira, L., 2009. Home range and spatial organization of maned wolves in the Brazilian grasslands. J. Mammal. 90, 150-157.

Dowd, J.L.B., Gese, E.M., Aubry, L.M., 2014. Winter space use of coyotes in high-elevation environments: behavioral adaptations to deep-snow landscapes. J. Ethol. 32, 29-41. http://dx.doi.org/10.1007/s10164-013-0390-0.

Fernandez, E.J., Tamborski, M.A., Pickens, S.R., Timberlake, W., 2009. Animal-visitor interactions in the modern zoo: conflicts and interventions. Appl. Anim. Behav. Sci. 120, 1-8. http://dx.doi.org/10.1016/j.applanim.2009.06.002.

Frair, J.L., Merrill, E.H., Visscher, D.R., Fortin, D., Beyer, H.L., Morales, J.M., 2005. Scales of movement by elk (Cervus elaphus) in response to heterogeneity in forage resources and predation risk. Landsc. Ecol. 20, 273-287. http://dx.doi.org/10.1007/s10980005-2075-8.

Gehrt, S.D., Anchor, C., White, L.A., 2009. Home range and landscape use of coyotes in a metropolitan landscape: conflict or coexistence? J. Mammal. 90, 1045-1057.

Gese, E.M., Ruff, R.L., 1997. Scent-marking by coyotes, Canis latrans: the influence of social and ecological factors. Anim. Behav. 54, 1155-1166. http://dx.doi.org/10. 1006/anbe.1997.0561.

Gese, E.M., Ruff, R.L., Crabtree, R.L., 1996. Foraging ecology of coyotes (Canis latrans): the influence of extrinsic factors and a dominance hierarchy. Can. J. Zool. 74, 769-783. http://dx.doi.org/10.1139/z96-089.

Gilbert-Norton, L.B., Leaver, L.A., Shivik, J.A., 2009. The effect of randomly altering the time and location of feeding on the behaviour of captive coyotes (Canis latrans). Appl. Anim. Behav. Sci. 120, 179-185. http://dx.doi.org/10.1016/j.applanim.2009.06. 007.

Gilloux, I., Gurnell, J., Shepherdson, D., 1992. An enrichment device for great apes. Anim. Welf. 1, 279-289.

Hosey, G.R., 2000. Zoo animals and their human audiences: what is the visitor effect? Anim. Welf. 9, 343-357.

Hosey, G., 2008. A preliminary model of human-animal relationships in the zoo. Appl. Anim. Behav. Sci. 109, 105-127. http://dx.doi.org/10.1016/j.applanim.2007.04. 013.

Hosey, G., 2013. Hediger revisited: how do zoo animals see us? J. Appl. Anim. Welf. Sci. 16, 338-359. http://dx.doi.org/10.1080/10888705.2013.827916.

Kazdin, A.E., 1977. Artifact, bias, and complexity of assessment: the ABCs of Reliability. J. Appl. Behav. Anal. 10, 141-150.

Kistler, C., Hegglin, D., Würbel, H., König, B., 2010. Structural enrichment and enclosure use in an opportunistic carnivore: the red fox (Vulpes vulpes). Anim. Welf. 19, $391-400$.

Kitchen, A.M., Gese, E.M., Schauster, E.R., 1999. Resource partitioning between coyotes and swift foxes: space, time, and diet. Can. J. Zool. 77, 1645-1656.

Kitchen, A.M., Gese, E.M., Karki, S.M., Schauster, E.R., 2005. Spatial ecology of swift fox social groups: from group formation to mate loss. J. Mammal. 86, 547-554.

Kuhar, C.W., 2008. Group differences in captive gorillas' reaction to large crowds. Appl. Anim. Behav. Sci. 110, 377-385. http://dx.doi.org/10.1016/j.applanim.2007.04. 011.

Larsen, M.J., Sherwen, S.L., Rault, J.-L., 2014. Number of nearby visitors and noise level affect vigilance in captive koalas. Appl. Anim. Behav. Sci. 154, 76-82. http://dx.doi. org/10.1016/j.applanim.2014.02.005.

Lenth, R.V., 2016. Least-squares means: the R package lsmeans. J. Stat. Softw. 69 (1), 1-33. http://dx.doi.org/10.18637/jss.v069.i01.

Mallapur, A., Qureshi, Q., Chellam, R., 2002. Enclosure design and space utilization by Indian Leopards (Panthera pardus) in four zoos in southern India. J. Appl. Anim. Welf. Sci. 5, 37-41. http://dx.doi.org/10.1207/S15327604JAWS0502.

Mallapur, A., Sinha, A., Waran, N., 2005. Influence of visitor presence on the behaviour of captive lion-tailed macaques (Macaca silenus) housed in Indian zoos. Appl. Anim. Behav. Sci. 94, 341-352. http://dx.doi.org/10.1016/j.applanim.2005.02.012.

Mason, G.J., 1991. Stereotypies: a critical review. Anim. Behav. 41, 1015-1037.

Mellen, J., MacPhee, M.S., 2001. Philosophy of environmental enrichment Past, present, and future. Zoo Biol. 20, 211-226.

Neale, J.C.C., Sacks, B.N., 2001. Resource utilization and interspecific relations of sympatric bobcats and coyotes. Oikos 94, 236-249.

Poessel, S.A., Gese, E.M., Young, J.K., 2017. Environmental factors influencing the occurrence of coyotes and conflicts in urban areas. Landsc. Urban Plan. 157, 259-269. http://dx.doi.org/10.1016/j.landurbplan.2016.05.022.

Poulle, M.L., Artois, M., Roeder, J.J., 1994. Dynamics of spatial relationships among members of a fox group (Vulpes vulpes: Mammalia: carnivora). J. Zool. 233, 93-106.

R Core Team, 2016. R: A Language and Environment for Statistical Computing. R Foundation for Statistical Computing, Vienna, Austria(URL https://www.R-project. $\operatorname{org} /$ ).

Renner, M.J., Lussier, J.P., 2002. Environmental enrichment for the captive spectacled bear (Tremarctos ornatus). Pharmacol. Biochem. Behav. 73, 279-283.

Roshier, D.A., Doerr, V.A., Doerr, E.D., 2008. Animal movement in dynamic landscapes: interaction between behavioural strategies and resource distributions. Oecologia 156, 465-477. http://dx.doi.org/10.1007/s00442-008-0987-0.

Séquin, E.S., Jaeger, M.M., Brussard, P.F., Barrett, R.H., 2003. Wariness of coyotes to camera traps relative to social status and territory boundaries. Can. J. Zool. 81 (12), 2015-2025.

Schell, C.J., Young, J.K., Lonsdorf, E.V., Mateo, J.M., Santymire, R.M., 2016. Olfactory attractants and parity affect prenatal androgens and territoriality of coyote breeding pairs. Physiol. Behav. 165, 43-54. http://dx.doi.org/10.1016/j.physbeh.2016.06. 038.

Sekar, M., Rajagopal, T., Archunan, G., 2008. Influence of zoo visitor presence on the behavior of captive Indian gaur (Bos gaurus gaurus) in a zoological park. J. Appl. Anim. Welf. Sci. 11, 352-357. http://dx.doi.org/10.1080/10888700802330093.

Shepherdson, D.J., Carlstead, K., Mellen, J.D., 1993. The influence of food presentation on the behavior of small cats in confined environments. Zoo Biol. 12, 203-216.

Shivik, J.A., Palmer, G.L., Gese, E.M., Osthaus, B., 2009. Captive coyotes compared to their counterparts in the wild: does environmental enrichment help? J. Appl. Anim. Welf. Sci. 12, 223-235. http://dx.doi.org/10.1080/10888700902955989.

Shyne, A., 2006. Meta-analytic review of the effects of enrichment on stereotypic behavior in zoo mammals. Zoo Biol. 25, 317-337. http://dx.doi.org/10.1002/zoo.

Skaug, H., Fournier, D., Nielsen, A., Magnusson, A., Bolker, B., 2013. Generalized Linear Mixed Models Using AD Model Builder.

Switalski, T.A., 2003. Coyote foraging ecology and vigilance in response to gray wolf reintroduction in Yellowstone National Park. Can. J. Zool. 81 (6), 985-993.

Veasey, J.S., Waran, N.K., Young, R.J., 1996. On comparing the behaviour of zoo housed animals with wild conspecifics as a welfare indicator. Anim. Welf. 5, 13-24.

Wells, D.L., 2005. A note on the influence of visitors on the behaviour and welfare of zoohoused gorillas. Appl. Anim. Behav. Sci. 93, 13-17. http://dx.doi.org/10.1016/j. applanim.2005.06.019.

Wemelsfelder, F., 1984. Animal boredom: is a scientific study of the subjective experiences of animals possible? In: Fox, M.W., Mickley, L.D. (Eds.), Advances in Animal Welfare Science 1984/85. The Humane Society of the United States, Washington, DC, pp. 115-154.

White, P.J., Ralls, K., Siniff, D.B., 2000. Nocturnal encounters between kit foxes. J. Mammal. 81, 456-461.

Woolway, E.E., Goodenough, A.E., 2017. Effects of visitor numbers on captive European red squirrels (Sciurus vulgaris) and impacts on visitor experience. Zoo Biol. 9999, 1-8. http://dx.doi.org/10.1002/zoo.21357. 